\title{
STrategi Optimasi Wisata MaSSAL di KaWASAN KonSERVASI TAMAN Wisata Alam Grojogan SEWU
}

\author{
HARIADi SisWANToro ${ }^{1}$, Sutrisno ANGgoro ${ }^{2}$, DWi P. SASongko ${ }^{3}$ \\ ${ }_{1}^{1}$ Program Studi Magister Ilmu Lingkungan, Program Pascasarjana Universitas Diponegoro, Semarang \\ ${ }^{2}$ Fakultas Perikanan dan Ilmu Kelautan Universitas Diponegoro Semarang \\ ${ }^{3}$ Fakultas Sains dan Matematika Universitas Diponegoro Semarang \\ Email : $\underline{\text { hariadi ssi@yahoo.com }}$
}

\begin{abstract}
ABSTRAK
Taman Wisata Alam Grojogan Sewu merupakan kawasan konservasi yang telah memberikan banyak manfaat bagi pemerintah dan aktivitas perekonomian setempat khususnya sebagai lokasi pariwisata alam. Namun pada akhirnya kegiatan wisata alam telah cenderung menjadi kegiatan wisata massal. Penelitian ini bertujuan untuk mengetahui daya dukung wisata alam yang didasarkan pada jumlah optimal pengunjung di areal wisata dan upaya untuk mengoptimalkannya. Metode yang digunakan adalah penilaian daya dukung efektif, penilaian persepsi para pelaku wisata (wisatawan dan penyedia sarana serta jasa wisata), kajian identifikasi keunggulan untuk pengembangannya dan penentuan strategi kebijakan publik melalui Analisis Hierarki Proses (AHP). Hasil penilaian menunjukkan bahwa daya dukung efektif wisata alam adalah 1.002 wisatawan per hari yang lebih tinggi daripada daya dukung aktualnya (926 wisatawan per hari). Wisatawan mendapatkan kepuasan dalam berwisata (95\%) dan ingin kembali berwisata di Grojogan Sewu (92\%). Hasil analisis AHP bahwa perlu dilakukan peningkatan kapasitas ekonomi kreatif masyarakat lokal dalam menghasilkan produk dan jasa wisata.
\end{abstract}

Kata kunci: daya dukung, wisata alam, Grojogan Sewu

\begin{abstract}
Grojogan Sewu's Nature Park is a conservation area which has provided many benefits to the government and the local economic activity especially as a nature tourism site. But in the end, a nature tourism activities have tended to be a mass tourist activities. This study aims to determine the carrying capacity of the natural attractions that are based on the optimal number of visitors in the area of tourism and the efforts to optimize it. The methods used are an effective carrying capacity assessment, an assessment of perceptions of tourism stakeholders (traveler and tourist facilities and tourist services), a review of the identification and a determination of excellence for the development of public policy strategies through Analytical Hierarchy Process (AHP). Assessment results show that the effective carrying capacity of nature is the 1.002 tourists per day higher than the actual carrying capacity ( 926 travelers per day). They get a satisfaction traveled (95\%) and want to get back traveling (92\%). AHP analysis result that is necessary to improve the capacity of local creative economy in providing products and services tourism.
\end{abstract}

Keywords: carrying capacity, nature tourism, Grojogan Sewu

\section{Pendahuluan}

Pembangunan pariwisata alam berkelanjutan telah menjadi pertimbangan dalam pengelolaan sumber daya alam yaitu bahwa kebutuhan ekonomi, sosial dan estetika dapat dipenuhi sambil memelihara integritas budaya, proses esensial ekologi, keanekaragaman biologi dan sistem penyangga kehidupan (Steck, 1999). Hal ini mengingat tujuan pariwisata adalah untuk mendapatkan rekreasi yaitu orang ingin diciptakan kembali atau memulihkan kekuatan dirinya baik fisik maupun spritual (Soemarwoto, 2004), namun juga mendukung upaya-upaya konservasi (Nugroho, 2011). 
Dewasa ini, aktivitas pariwisata di kawasan lindung/konservasi cenderung meningkat bersamaan dengan peningkatan kesadaran tentang konservasi alam (Pickering dan Hill, 2007). Peningkatan pariwisata ini sejalan dengan adanya peningkatan aktivitas wisata alam bebas antara lain berupa jalan santai di alam bebas/ hiking, lintas alam/ trekking atau pun bersepeda gunung. Meski bermanfaat bagi manusia, di sisi lain, aktivitas ini dapat berdampak secara ekologis pada ekosistem hutan (Rosalino dan Grilo, 2011).

Secara umum, dikenal dua tipe pariwisata di kawasan konservasi yaitu dalam skala kecil atau minat khusus (ekowisata) yang mungkin akan memberikan dampak yang kecil bagi ekosistem dan dalam skala besar/ wisata massal yang melibatkan banyak komponen dan akan memberi dampak besar bagi ekosistem (McCool dan Moisey, 2008). Kecenderungan ekowisata secara internasional memang mengalami peningkatan (Fandeli dan Nurdin, 2005), namun secara ekonomi, wisata massal dengan jumlah wisatawan berskala besar dan terus menerus dipandang lebih menguntungkan daripada ekowisata dengan jumlah wisatawan berskala kecil dan tidak menentu.

Salah satu indikator pengelolaan adalah daya dukung wisata alam (Cifuentes (1992); Soemarwoto (2004)). Organisasi Wisata dunia atau World Tourism Organisation (WTO) memberi pengertian daya dukung wisata sebagai jumlah maksimum orang yang boleh mengunjungi satu tempat wisata pada saat bersamaan tanpa menyebabkan kerusakan lingkungan fisik, ekonomi dan sosial budaya dan penurunan kualitas yang merugikan bagi kepuasan wisatawan (Livina, 2009). Kepuasan wisatawan adalah indikator pengakuan atas keberhasilan kapasitas dan pengelolaan tempat wisata. Kepuasan wisatawan merupakan suatu pernyataan loyalitas dalam berwisata dan bermakna positif. Pemahaman terhadap kepuasan wisatawan menjadi sesuatu yang penting dalam memposisikan strategi bagi tempat wisata (Cerina et al., 2011). Pada dasarnya, ada dua aspek dalam pemanfaatan wisata yang secara integral berkaitan dengan daya dukung yaitu melindungi sumber daya dan kualitas pengalaman berwisata (Sayan dan Atik, 2011).

Salah satu kawasan konservasi yang dimanfatkan untuk kepentingan wisata alam adalah Taman Wisata Alam (TWA) Grojogan Sewu. Kawasan ini merupakan kawasan pelestarian alam yang berada pada koordinat geografis 7039'17"-7039'49"LS dan 4018'53"4020'16"BT, tepatnya berada di Desa Tawangmangu, Kecamatan Tawangmangu, Kabupaten Karanganyar, Provinsi Jawa Tengah. TWA Grojogan Sewu ditunjuk sebagai kawasan taman wisata alam berdasarkan Surat Keputusan Menteri Pertanian Nomor 264/Kpts/Um/10/1968 tanggal 12 Oktober 1968 dengan luas 64,30hektar. Pengusahaan Pariwisata Alam di kawasan ini dilakukan oleh PT Duta Indonesia
Djaya berdasarkan Surat Keputusan Menteri Pertanian No. 305/Kpts/Um/1969 selama 20 tahun dengan luas 20 hektar. Selanjutnya telah diperpanjang melalui Keputusan Direktur Jenderal Perlindungan Hutan dan Konservasi Alam Nomor 51/Kpts/Dj-VI/1988 untuk jangka waktu 20 tahun hingga tahun 2009. Dan telah diperpanjang lagi melalui Surat Keputusan Menteri Kehutanan Nomor SK.661/Menhut-II/2009 tanggal 15 Oktober 2009 tentang Perpanjangan Izin Pengusahaan Pariwisata Alam Seluas 20,3 ha di Blok Pemanfaatan TWA Grojogan Sewu atas nama PT Duta Indonesia Djaya (BKSDA Jateng, 2009; Duta Indonesia Djaya, 2009).

Oleh karena itu, guna mengoptimalkan wisata alam TWA Grojogan Sewu agar tetap berkelanjutan, maka perlu diketahui beberapa hal terkait aspek pengelolaannya yaitu dari aspek jumlah pengunjung yang dapat diakomodasi dalam menikmati aktivitas wisata alam dan dari upaya yang dapat dilakukan untuk mengoptimalkan areal wisata massal.

\section{Material Dan Metode Penelitian}

Daya dukung fisik (Physical Carrying Capacity/ PCC) merupakan jumlah maksimum wisatawan yang secara fisik tercukupi oleh ruang yang disediakan pada waktu tertentu. Daya dukung riil (Real Carrying Capacity/ RCC) merupakan jumlah pengunjung yang diperbolehkan berkunjung ke suatu obyek wisata dengan faktor koreksi (Correction Factor/CF) yang diambil dari karakteristik obyek yang diterapkan pada PCC. Daya dukung efektif (Effective Carrying Capacity/ ECC) merupakan jumlah kunjungan maksimum di mana obyek tetap lestari pada tingkat managemen (Management Capacity/MC) yang tersedia (Cifuentes, 1992; Khair, 2008; Sustri, 2009; Sayan dan Atik, 2011). Pendekatan ECC ini memperhitungkan RCC sebagai PCC yang dipengaruhi oleh variabel ekosistem yaitu variabel biotik dan variabel abiotik. Kedua variabel tersebut merupakan faktor koreksi $\left(\mathrm{Cf}_{\mathrm{n}}\right)$ dari penentuan nilai RCC. Faktor koreksi akan menjadi faktor pembatas bagi daya dukung efektif.

Untuk mengetahui nilai daya dukung efektif tersebut, metodologi yang digunakan adalah Metode Cifuentes (1992) karena telah disarankan oleh IUCN (Sayan dan Atik, 2011). Perhitungannya adalah menggunakan persamaan-persamaan sebagai berikut:

$$
\begin{aligned}
& E C C=P C C \times M C \\
& P C C=A \times \frac{1}{B} \times R f
\end{aligned}
$$

Keterangan: B adalah luas area yang dibutuhkan oleh seorang wisatawan untuk berwisata dengan tetap memperoleh kepuasan. Kebutuhan areal berwisata tiap orang untuk kegiatan berenang adalah $27 \mathrm{~m}^{2}$, berperahu $49 \mathrm{~m}^{2}$, berpiknik $65 \mathrm{~m}^{2}$ dan berkemah $90 \mathrm{~m}^{2}$; Rf adalah faktor rotasi kunjungan dalam satu hari atau merupakan perbandingan antara jam buka obyke wisata dibagi dengan rata-rata lama kunjungan wisatawan. 


$$
M C=\frac{R_{n}}{R_{t}} \times 100 \%
$$

Keterangan: $R_{n}$ adalah jumlah petugas yang ada; $R_{t}$ adalah jumlah petugas yang dibutuhkan.

$$
R C C=P C C-C f_{1}+C f_{2}+\ldots . . C f_{n}
$$

Keterangan: $\mathrm{Cf}_{\mathrm{n}}$ adalah faktor pereduksi/koreksi ke-n terkait dengan variabel ke-n

Atau persamaan tersebut dapat diubah dalam bentuk persentase sehingga menjadi:

$$
\begin{aligned}
& R C C=P C C \times \frac{100-C f_{1}}{100} \times \frac{100-C f_{2}}{100} \times \ldots \ldots . . \times \frac{100-C f_{n}}{100} \\
& C f_{n}=\frac{M_{n}}{M_{t}} \times 100 \%
\end{aligned}
$$

Keterangan: $M_{n}$ adalah kondisi nyata pada variabel $f_{n}$ terhitung; $\mathrm{M}_{\mathrm{t}}$ adalah batas maksimum pada variabel $\mathrm{Cf}_{\mathrm{n}}$ tersebut

Variabel biotik (diversitas pohon, diversitas burung, gangguan terhadap musim kawin monyet ekor panjang) dan variabel abiotik (potensi lanskap, kelerengan, kepekaan erosi tanah dan curah hujan). Variabelvariabel tersebut dipilih, karena (1) dapat mempengaruhi kelestarian ekosistem di areal wisata yang dikunjungi; dan (2) mempengaruhi kepuasan berkunjung dari wisatawan. Variabel-variabel tersebut selanjutnya merupakan faktor-faktor pembatas terhadap keberlangsungan interaksi wisatawan dan ekosistem di areal wisata di TWA Grojogan Sewu.

Variabel biotik merupakan flora dan fauna yang terdapat di TWA Grojogan Sewu. TWA ini memiliki karakteristik flora berupa vegetasi hutan yang didominasi oleh pepohonan pinus (Pinus mercusii) dengan fauna berupa monyet ekor panjang dan beberapa jenis burung (BKSDA Jateng, 2009). Selanjutnya data-data yang diperoleh kemudian dihitung untuk memperoleh indeks dominansi $(\lambda)$ untuk menghitung indeks diversitas simpson (ID) masing-masing untuk pepohonan dan burung. Nilai berkisar antara 0 sampai dengan 1 . Nilai ini merupakan faktor koreksi pada perhitungan RCC.

$$
\begin{aligned}
& \mathrm{ID}=1-\lambda \\
& \lambda=\frac{\sum_{i=1}^{S} n i(n i-1)}{n(n-1)}
\end{aligned}
$$

Keterangan: s adalah jumlah spesies; ni adalah jumlah individu spesies ke-i; $\mathrm{n}$ adalah jumlah individu semua spesies.

Sedangkan untuk faktor koreksi ECC dalam bentuk gangguan terhadap musim kawin monyet ekor panjang (Khair, 2006) diperhitungkan dengan persamaan sebagai berikut:

$$
C f_{n}=\frac{G_{n}}{G_{t}} \times 100 \%
$$

Keterangan: $G_{n}$ adalah jumlah bulan terjadinya musim kawin; sedangkan $G_{t}$ adalah jumlah bulan dalam setahun.

Faktor koreksi pada variabel abiotik ditentukan berdasarkan potensi lanskap atau bentang alam, kelerengan, kepekaan erosi tanah dan curah hujan. Hal ini karena topografi di areal wisata yang berbukit-bukit sehingga pembangunan pada unsur landskap bernilai tinggi harus dikonservasi. Sedangkan unsur landskap bernilai rendah dapat dimanfaatkan untuk area pembangunan infrastruktur. Indeks potensi landskap dinilai berdasarkan poin kriteria pada masing-masing unsur lanskap yaitu bentuk (landform), vegetasi (vegetation), warna (colour), pemandangan (scenery), kelangkaan (scarcity) dan modifikasi struktural (indeks Bureau of Land Management (Sustri, 2009; Fandeli dan Muhammad, 2009).

Kondisi kelerengan turut mempengaruhi wisatawan dalam menikmati alam. Kelerengan yang terjal akan membutuhkan lebih banyak tenaga untuk mendaki atau akan dapat berakibat kelelahan bagi wisatawan. Kepekaan erosi tanah akan mempengaruhi kerentanan terhadap risiko bencana sehingga akan mempengaruhi wisatawan dalam berkunjung.

Curah hujan mempengaruhi aktivitas wisatawan. Semakin tinggi curah hujan, akan dapat mengganggu kenyamanan berwisata. Meski dari sisi ekologis, kestabilan curah hujan dapat menjaga debit air di Sungai Samin sehingga air terjun Grojogan Sewu relatif stabil sepanjang tahun. Penilaian faktor koreksi iklim ini adalah dalam bentuk rasio/ indeks nilai Q selama sepuluh tahun terakhir (Lakitan, 1997).

$$
Q=\frac{\sum \text { rata }- \text { ratabulan kering }}{\sum \text { rata }- \text { ratabulan basah }}
$$

Keterangan: bulan kering adalah bulan dengan curah hujan <60 mm; bulan lembab adalah bulan dengan curah hujan 60-100 $\mathrm{mm}$; bulan basah adalah bulan dengan curah hujan $>100 \mathrm{~mm}$.

Pada penelitian ini digunakan variabel sosial sebagai bagian dari penilaian persepsi para pelaku wisata terhadap aktivitas pariwisata di TWA Grojogan Sewu. Responden yang dibutuhkan terdiri dari tiga kelompok yaitu wisatawan, pedagang kaki lima yang berniaga di dalam areal wisata TWA yang terorganisir dalam bentuk Persatuan Pedagang Bina Wisata (Perdabita) dan pengelola (PT Duta Indonesia Djaya). Jumlah responden ditentukan menggunakan persamaan Sevilla (Fandeli, 2000).

$$
n=\frac{N}{1+N e^{2}} \times 100 \%
$$

Keterangan: $\mathrm{N}$ adalah ukuran populasi responden untuk masing-masing kelompok; $\mathrm{n}$ adalah jumlah sampel responden; e tingkat ketelitian sebesar $\leq 10 \%$. 
Hariadi Siswantoro, Sutrisno Anggoro, Dwi P. Sasongko. 2012., Strategi Optimasi Wisata Massal di Kawasan Konservasi Taman Wisata Alam Grojogan SEWU. Jurnal Ilmu Lingkungan, Vol 10 (2): 100-110. http://ejournal.undip.ac.id/index.php/ilmulingkungan

Persepsi responden digali dengan menggunakan kuisioner tertutup. Materi kuisioner meliputi (1) profil responden (umur, jenis kelamin, pendidikan, domisili), (2) informasi obyek wisata (daya tarik obyek wisata, sumber informasi/promosi), (3) pemahaman konservasi dan lingkungan (sikap dan perilaku), (4) aktivitas wisata (tujuan berwisata, lama berwisata, aktivitas berwisata, kepuasan berwisata), dan (5) pengelolaan obyek wisata (fasilitas, pelayanan, ketergangguan, evaluasi). Data yang diperoleh dari kuesioner adalah data ordinal berupa pengukuran tingkatan atau gradasi persepsi dari sangat negatif hingga sangat positif. Skala yang digunakan untuk mengukur sikap, pendapat atau persepsi seseorang atau sekolompok orang tentang fenomena sosial tersebut adalah skala likert dengan modifikasi. Selanjutnya dilakukan perumusan strategi menggunakan analisis SWOT (Rangkuti, 1998) dan Analytical Hierarchy Process (AHP) (Saaty, 1993) untuk menentukan strategi kebijakan (Subarsono, 2005) dalam pengelolaan wisata alam di TWA Grojogan Sewu.

\section{Hasil Dan Pembahasan}

\subsection{Daya Dukung Wisata Alam}

Berdasarkan hasil pengamatan dapat diketahui bahwa luas areal wisata yang dikelola PT Duta Indonesia Djaya di TWA Grojogan Sewu adalah 20,3 ha atau $203.000 \mathrm{~m}^{2}$. Obyek wisata buka dari jam 07.30-16.00 Waktu Indonesia Barat atau sama dengan 8,5 jam setiap hari. Umumnya aktivitas berwisata adalah dalam bentuk berpiknik, sehingga luas areal yang dibutuhkan tiap orang untuk berpiknik dengan nyaman adalah $65 \mathrm{~m}^{2}$ (Fandeli dan Muhammad (2009). Lama waktu kunjungan wisatawan umumnya adalah 3 jam. Dengan menggunakan persamaan (2) maka dapat diperoleh hasil nilai PCC sebesar 8.849 orang.

Jadi nilai daya dukung fisik areal wisata adalah 8.849 orang per hari, yang berarti bahwa areal wisata TWA Grojogan Sewu secara fisik mampu menampung sejumlah wisatawan tersebut setiap hari. Selanjutnya dapat diperhitungan daya dukung riil areal wisata dengan memperhitungkan faktor koreksi.

- Faktor koreksi dari variabel biotik berupa vegetasi pohon, dapat ditentukan dengan menghitung jenis dan jumlah vegetasi di sekitar areal wisata. Lokasi yang diperhitungkan adalah sepanjang trek wisata dan areal wisata dengan radius terjauh adalah 10 meter. Jenis yang ditemukan sebanyak 23 spesies dengan keseluruhan sebanyak 655 individu. Jenisjenis tersebut antara lain Pinus (Pinus merkusii) sebanyak 374 pohon, Pasang (Quercus sp) sebanyak 54 pohon, Suren (Toona sureni) 43 batang. Perhitungan indeks keragaman Simpson dilakukan dengan menggunakan persamaan (7) dan didapatkan hasil $I D=0,655$

- Faktor koreksi dari variabel biotik berupa satwa burung atau avifauna, dapat ditentukan dengan menghitung jenis dan jumlah burung di sekitar areal wisata. Lokasi yang diperhitungkan adalah sepanjang trek wisata dan areal wisata dengan radius terjauh adalah 50 meter. Jenis yang ditemukan sebanyak 4 spesies dengan keseluruhan jumlah individu 13 ekor. Jenis-jenis tersebut antara lain Sri gunting (Dicrurus macrocercus), Cucak hijau, Cekakak sungai (Halcyon sp) dan Kutilang (Pycnonotus aurigaster). Analog dengan perhitungan Indeks Keragaman Simpson, maka didapatkan hasil $I D=0,615$

- Faktor koreksi dari variabel biotik adalah satwa dalam hal ini adalah indeks ketergangguan musim kawin monyet ekor panjang (Macaca fascicularis). Namun ternyata berdasarkan hasil pengamatan, diperkirakan musim kawin terjadi sepanjang tahun 12 bulan tiap tahun. Tidak ada periode waktu khusus bagi monyet untuk kawin. Hal ini berarti bahwa bagi monyet, keberadaan pengunjung TWA ternyata bukan merupakan gangguan baginya untuk melangsungkan proses reproduksi. Meski di sisi lain perilaku agresif monyet (Djuwantoko et al., 2008) masih diperlihatkan kepada pengunjung.

- Faktor koreksi dari variabel abiotik adalah indeks potensi landskap (Bureau of Land Management (1985) dalam Fandeli dan Muhammad (2009); Sustri (2009)). Berdasarkan hasil pengamatan, nilai indeks sebesar 0,63.

- Faktor koreksi dari variabel abiotik adalah kelerengan (SK.Menteri Pertanian No.837/KPTS/UM/11/1980 dalam Muta'ali (2012)). Berdasarkan pengamatan lapangan, topografi areal wisata yang dikunjungi intensif oleh wisatawan dapat dikelompokkan dalam enam segmen. Keenam segmen tersebut dinilai berdasarkan tingkat kecuraman lereng secara umum. Penilaian dilakukan dengan menggunakan sistem skoring pada kriteria kelas lereng dan hasilnya Indeks kelerengan yaitu sebesar 50 .

- Faktor koreksi abiotik berikutnya adalah indeks kepekaan erosi (SK.Menteri Pertanian No.837/KPTS/UM/11/1980 dalam Muta'ali (2012)). Berdasarkan data sekunder, jenis tanah di TWA Grojogan Sewu adalah jenis andosol. Tanah ini memiliki kepekaan tinggi (nilai 60).

- Faktor koreksi abiotik selanjutnya adalah curah hujan. Berdasarkan data curah hujan Kecamatan Tawangmangu Kabupaten Karanganyar Tahun 20012011, maka diperoleh jumlah bulan kering (bulan dengan curah hujan $<60 \mathrm{~mm}$ ) sebesar 33 dan jumlah bulan basah (bulan dengan curah hujan $>100 \mathrm{~mm}$ ) sebesar 77. Indeks nilai $Q$ yang merupakan perbandingan jumlah bulan kering dan bulan basah selama sepuluh tahun terakhir, adalah sebesar $42,86 \%$.

- Jumlah tenaga kerja tetap pengelola adalah 25 orang (Duta Indonesia Djaya, 2009). Jumlah tersebut merupakan sumber daya manusia yang dibutuhkan untuk mengelola areal wisata. Dengan memperhitungkan kemungkinan ketidakhadiran di tempat tugas $\pm 10 \%$ per hari, maka setiap hari 
diperkirakan jumlah tenaga kerja yang aktif di lapangan sebanyak 22 orang.

- Berdasarkan perhitungan dengan menggunakan persamaan (6), (5) dan (1), maka dapat ditentukan nilai daya dukung efektif wisata alam di areal wisata TWA Grojogan Sewu sebesar 1.002 orang wisatawan per hari.

Fandeli dan Suyanto (1999) pernah melakukan penelitian tentang daya dukung psikologis wisata alam terhadap para pengunjung di TWA Grojogan Sewu. Metode yang digunakan adalah menggunakan progam linear dengan mempertimbangkan variabel luas ruang gerak wisatawan, keterbatasan waktu dan keterbatasan petugas pelayanan objek wisata. Program linear untuk mengoptimalkan fungsi tujuan dengan mempertimbangkan fungsi kendala mendapatkan hasil bahwa daya dukung psikologis TWA Grojogan Sewu adalah sebesar 3.700 orang/hari.

Berdasarkan data jumlah pengunjung TWA Grojogan Sewu tiap bulan selama tujuh tahun terakhir yaitu tahun 2005 sampai dengan tahun 2011 maka bila dilakukan perhitungan rata-rata jumlah pengunjung per hari selama periode tersebut adalah sebesar 926. Nilai ini masih lebih kecil dibandingkan nilai daya dukung wisata alam. Oleh karena itu, maka daya dukung wisata alam TWA Grojogan Sewu masih belum terlampaui. Kondisi ini akan menjadi peluang bagi pengembangan pariwisata alam.

\subsection{Persepsi Responden Pelaku Wisata}

Hasil penilaian daya dukung tersebut di atas perlu diimbangi dengan menggali lebih dalam potensi dan dampak yang mungkin ditimbulkan oleh aktivitas pariwisata alam. Menurut Farrell dan Marion (2002), nilai daya dukung lebih menekankan pada pentingnya jumlah penggunaan suatu areal. Di sisi lain, bagi pengunjung, pengalaman berwisata tidak hanya dipengaruhi oleh jumlah pengunjung, melainkan juga aktivitas berwisata, perilaku pengunjung dan tingkat pendidikan dan harapan/tujuan berwisata. Menurut Gurung (2010), pertumbuhan jumlah pengunjung di kawasan konservasi dapat mempengaruhi integritas ekologi dalam cakupan yang lebih luas pada ekosistem alaminya. Hal ini juga merupakan umpan balik dari pengelolaan kawasan konservasi bagi masyarakat dalam memberikan manfaat optimal berwisata alam.

Penggalian potensi dan dampak ini dilakukan melalui wawancara dengan responden yang berinteraksi secara langsung dalam aktivitas wisata alam. Responden terdiri dari wisatawan, pedagang kaki lima dan pengelola yang berada di areal wisata TWA Grojogan Sewu. Jumlah responden wisatawan ditentukan berdasarkan persamaan (12). Hasil penelitian didapatkan jumlah responden (n) wisatawan sebesar 283 orang $(\mathrm{N}=926)$, responden Perdabita 61 orang $(\mathrm{N}=$
142 orang), responden pengelola 24 orang $(\mathrm{N}=25$ orang).

Responden pedagang kaki lima yang dimaksud merupakan anggota jasa wisata yang tergabung dalam Persatuan Pedagang Bina Wisata (Perdabita) TWA Grojogan Sewu yang berniaga di dalam TWA. Perdabita terdiri dari pedagang kios makanan dan minuman, pedagang sate kelinci/ayam, jasa fotografi dan jasa penyewaan tikar.

Persepsi para responden terhadap pengelolaan TWA Grojogan Sewu menunjukkan bahwa hampir 60\% wisatawan menyukai kelengkapan sarana prasarana wisata, kebersihan dan pengelolaan sampah. Untuk pelayanan bertema edukatif dan penyebaran pengunjung dianggap cukup memadai. Namun untuk penampilan atraksi massal, baik wisatawan, Perdabita maupun pengelola hanya kurang dari $40 \%$ yang menyukainya. Interaksi wisatawan dan monyet ekor panjang disukai oleh $50 \%$ wisatawan dan $15 \%$ tidak menyukainya. Namun secara keseluruhan 95\% wisatawan merasa puas berwisata dan 92\% ingin kembali berwisata di TWA.

\subsection{Strategi Optimasi Pengelolaan Wisata Alam}

Pada analisis matrik SWOT, kombinasi antara kekuatanpeluang, kekuatan-ancaman, kelemahan-peluang dan kelemahan-ancaman dapat memunculkan suatu upaya untuk melengkapi ketidaksempurnaan kondisi internal dan eksternal. Upaya ini dimunculkan dalam bentuk pernyataan alternatif strategi. Tabel 1 berikut memperlihatkan hal tersebut.

Cita-cita dan agenda utama pembangunan berkelanjutan adalah upaya untuk mensinkronkan, mengintegrasikan dan memberi bobot yang sama bagi tiga aspek pembangunan yaitu aspek ekonomi, aspek sosial budaya dan aspek lingkungan hidup (Keraf, 2010) atau ekologi (Muta'ali, 2012). Menindaklanjuti hasil analisis SWOT, telah dilakukan In Depth Interview (wawancara mendalam) kepada beberapa pemangku kepentingan. Wawancara ini ditujukan kepada BKSDA Jawa Tengah (termasuk Seksi Konservasi Wilayah I Surakarta dan Resort Grojogan Sewu), Dinas Pariwisata Kabupaten Karanganyar, Badan Lingkungan Hidup Kabupaten Karanganyar, PT Duta Indonesia Djaya dan Perdabita TWA Grojogan Sewu. Wawancara ini dilakukan untuk memperdalam pemahaman pembangunan pariwisata berkelanjutan ditinjau dari aspek ekonomi, sosial dan ekologi dengan mendasarkan pada hasil analisis SWOT.

Berdasarkan wawancara tersebut, maka dapat dirumuskan isu-isu pengembangan pariwisata alam di TWA Grojogan Sewu sebagai berikut:

1. Perlunya peningkatan kapasitas ekonomi kreatif masyarakat lokal (A1) 
Hariadi Siswantoro, Sutrisno Anggoro, Dwi P. Sasongko. 2012., Strategi Optimasi Wisata Massal di Kawasan Konservasi Taman Wisata Alam Grojogan SEWU. Jurnal Ilmu Lingkungan, Vol 10 (2): 100-110. http://ejournal.undip.ac.id/index.php/ilmulingkungan

Tabel 1. Rekapitulasi Analisis Matrik SWOT

\begin{tabular}{|c|c|c|c|}
\hline $\begin{array}{l}\text { EFAS } \\
\text { (Eksternal Factor } \\
\text { Analysis Summary) }\end{array}$ & $\begin{array}{r}\text { IFAS } \\
\text { (Internal Factor Analysis } \\
\text { Summary) }\end{array}$ & $\begin{array}{l}\text { Kekuatan (Strength) } \\
\text { - Areal wisata di TWA telah } \\
\text { dikelola secara legal. } \\
\text { - Telah diakui oleh Pemda } \\
\text { setempat. } \\
\text { - Ekosistem hutan masih } \\
\text { terpelihara } \\
\text { - Telah terbentuk } \\
\text { kelembagaan lokal } \\
\text { (Perdabita) }\end{array}$ & $\begin{array}{l}\text { Kelemahan (Weakness) } \\
\text { - Perilaku monyet cukup } \\
\text { mengganggu kenyamanan } \\
( \pm 10 \%) \text {. } \\
\text { - Pengenalan TWA dari } \\
\text { teman/saudara }(80 \%)\end{array}$ \\
\hline
\end{tabular}

\section{Peluang (Opportunities)}

- Daya dukung wisata alam belum terlampaui.

- Berada di jalur obyek wisata lain di Karanganyar dan sekitarnya.

- Wisatawan umumnya (60\%) peduli dan bersedia berpartisipasi dalam hal konservasi dan lingkungan.

- Wisatawan merasa puas berwisata (95\%) dan ingin mengulang kembali (92\%).

- Wisatawan menjadikan TWA sebagai tujuan utama berwisata (73\%) dan ingin menikmati suasana alami/relaksasi (80\%).

\section{Strategi S-0: \\ "keunggulan kompetitif" \\ - Perlu dilakukan edukasi tentang konservasi dan lingkungan khususya bagi wisatawan agar nuansa wisata alam lebih bermanfaat.}

\author{
Strategi W-0: \\ "mobilisasi kelemahan" \\ - Perlu dilakukan promosi \\ melalui media massa \\ secara efektif. \\ - Perlu dilakukan upaya \\ untuk mengendalikan \\ perilaku monyet.
}

Ancaman (Threat)

- Berada di lereng yang curam dengan tanah peka erosi/andosol.

- Air terjun berkaitan dengan kelestarian hutan di Hulu Kali Samin.

- Limbah plastik masih mendominasi sebagai sisa kemasan produk makanan dan minuman.

- Perdabita menyukai bila wisatawan berlimpah (70\%) namun hanya 40\% wisatawan yang menyukai produk makanan dan minuman.

\section{Strategi S-T:}

"keunggulan komparatif"

- Perlu dilakukan upaya pengembangan kapasitas pengetahuan dan keterampilan penyedia jasa wisata dalam menjual layanan jasa wisata.

- Perlu pengembangan produk dan jasa wisata secara kreatif.

\section{Strategi W-T:}

"demobilisasi kelemahan"

- Perlu dilakukan upaya pengendalian stabilitas lereng dari bahaya longsor.

- Perlu dilakukan perlindungan tanah dari erosi.
Hal ini merupakan upaya untuk meningkatkan kapasitas masyarakat (pengetahuan dan keterampilan) khususnya pelaku pariwisata agar lebih kreatif dan unik dalam memproduksi dan menjual jasa/produk wisata guna meningkatkan kepuasan berwisata.

2. Perlunya menaikkan harga karcis masuk TWA (A2) Hal ini bertujuan untuk membatasi jumlah pengunjung, mendidik dan meningkatkan tanggung jawab wisatawan terhadap arti pentingnya kawasan konservasi, meningkatkan kualitas berwisata alam dan memberikan perlindungan ekosistem terhadap tekanan pengunjung. Menaikkan harga karcis juga akan meningkatkan nilai pentingnya aset ekologi di mata wisatawan yang akan berimbas pada meningkatnya apresiasi terhadap kawasan konservasi.

3. Perlu dilakukan upaya untuk meningkatkan dan memadukan promosi/pemasaran paket wisata alam beserta produk lokal (A3)

Pengemasan promosi dan pemasaran obyek wisata alam beserta produk-produk lokal (barang/kerajinan, pertanian dan jasa wisata) dalam satu keterpaduan baik melalui media massa (majalah, leaflet/brosur, internet dan sebagainya) maupun melalui jaringan lembaga kepariwisataan. Hal ini memerlukan keterpaduan pemerintah dan swasta.

4. Perlu dilakukan upaya edukasi konservasi dan lingkungan bagi wisatawan dan masyarakat (A4) Hal ini dilakukan dalam rangka memberikan pemahaman konservasi dan lingkungan terhadap wisatawan dan masyarakat baik yang melibatkan secara langsung dalam aktivitas bernuansa konservasi dan lingkungan maupun yang secara tidak langsung melalui himbauan, pengenalan karakteristik pepohonan dan satwa, penggunaan slogan dan lainnya.

5. Perlu dipopulerkan kembali atraksi wisata kesenian lokal (A5)

Hal ini untuk mengangkat kembali kesenian tradisional sebagai budaya daerah setempat, yang di sisi lain akan mengurangi tekanan arus wisatawan di TWA GS dan mendistribusikannya ke obyek wisata lain di Tawangmangu. 
6. Perlu dilakukan penguatan komunikasi antar para pihak (forum/musyawarah) (A6)

Hal ini untuk menjalin komunikasi dalam rangka menyamakan persepsi dan sinergi program kegiatan di masing-masing stakeholder dalam mewujudkan tujuan pariwisata alam berkelanjutan di Kecamatan Tawangmangu. Keterpaduan pengelolaan pariwisata di Kabupaten Karanganyar secara umum, akan dapat mengoptimalkan daya dukung wisata di TWA Grojogan Sewu.

7. Perlu dilakukan upaya untuk memperkuat stabilitas lereng dan perlindungan tanah (A7)

Hal ini dilakukan dalam rangka pengendalian stabilitas lereng dan perlindungan tanah baik secara buatan (terasiring; biopori, sumur resapan) maupun secara alami (penanaman bibit pohon). Tujuannya adalah untuk memperkecil kerentanan longsor dan mempertahankan kelestarian kawasan konservasi.

8. Perlu dilakukan penataan zona/blok TWA Grojogan Sewu secara keseluruhan (site plan) (A8)

Hal ini untuk mempertegas fungsi zona/blok pemanfaatan, blok pemanfaatan intensif dan blok kelestarian hutan yang menjadi bagian dari ciri khas obyek wisata tetap terjaga. Hingga saat ini, sebagai kawasan pelestarian alam, TWA Grojogan Sewu belum memiliki Rencana Pengelolaan TWA dan Rencana Tapak Pengelolaan Wisata.

9. Perlu dilakukan upaya untuk mengendalikan agresifitas monyet ekor panjang (A9)

Hal ini perlu dilakukan untuk mengurangi ketergantungan monyet terhadap pemberian pakan dari wisatawan sebagai atraksi wisata dan pada akhirnya akan mengurangi perilaku agresif monyet yang mengganggu wisatawan.

Berdasarkan perumusan isu-isu strategis, maka isu-isu strategis tersebut dilakukan pengelompokan dalam tiga aspek keberlanjutan pembangunan pariwisata alam yaitu tiga kriteria yaitu aspek ekonomi, aspek sosial budaya dan aspek ekologi. Alternatif strategi yang dihasilkan adalah sebagaimana Gambar $1 \mathrm{a}$.

Berdasarkan analisis pilihan para pihak tersebut terhadap ketiga aspek keberlanjutan pembangunan pariwisata dalam rangka optimasi daya dukung wisata

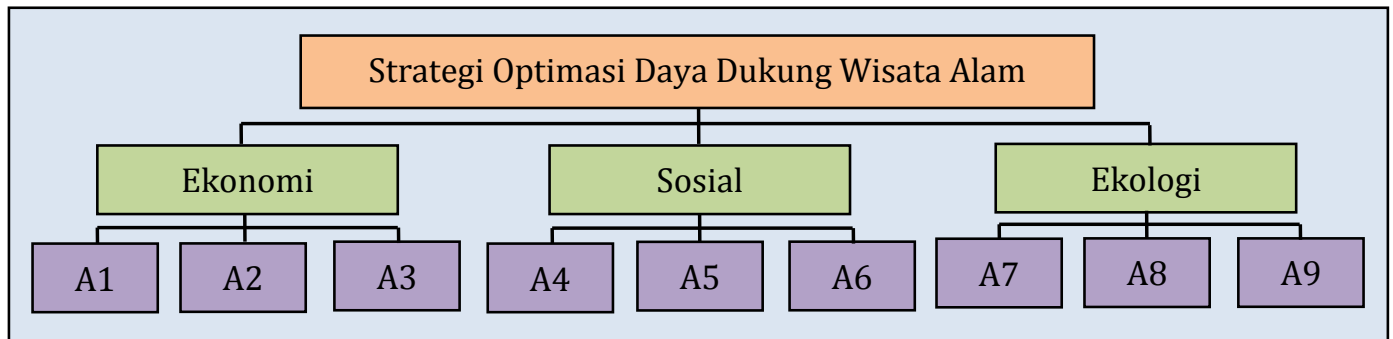

Gambar 1 (a)

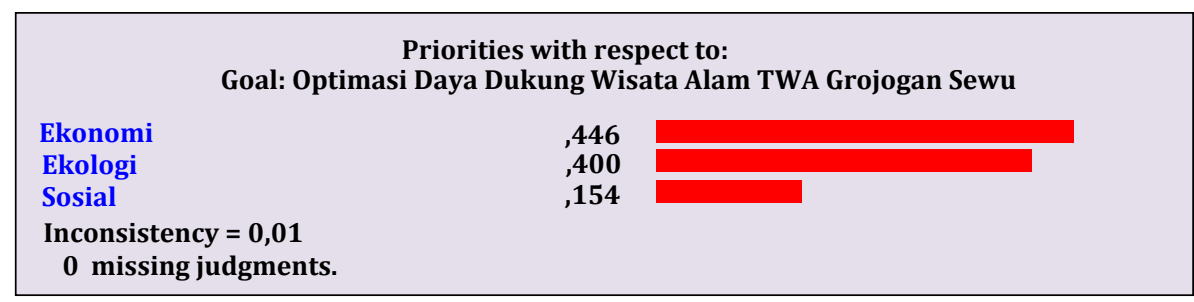

Gambar 1 (b)

$\begin{array}{lr}\text { (A1) Ekonomi kreatif } & , 254 \\ \text { (A7) Penguatan lereng } & , 228 \\ \text { (A2) Naikkan karcis } & , 134 \\ \text { (A8) Penataan blok } & , 116 \\ \text { (A3) Memadukan promosi } & , 088 \\ \text { (A4) Fdukasi wstw \& masv } & , 088 \\ \text { (A9) Pengendalian monyet } & , 041 \\ \text { (A5) Atraksi kesenian } & , 028 \\ \text { (A6) Komunikasi stakeholder } & , 023\end{array}$

(A6) Komunikasi stakeholder 023

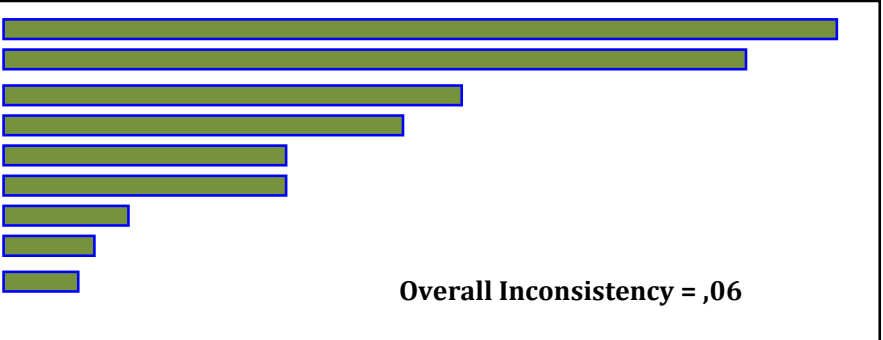

Gambar 1 (c)

Gambar 1. Analisis Hierarki Proses. (a) Bagan Strategi Optimasi Daya Dukung Wisata Alam Dengan AHP; (b) Kriteria Aspek Prioritas Optimasi Daya Dukung Wisata Alam; (c) Prioritas Kriteria dan Alternatif Strategi Ontimasi Dava Dukung Wisata Alam

perlindungan pada kawasan konservasi seluas 60 ha melalui penataan batas secara definitif agar alam menunjukkan hasil bahwa aspek ekonomi masih dianggap sebagai pendorong aktivitas pariwisata alam 
Hariadi Siswantoro, Sutrisno Anggoro, Dwi P. Sasongko. 2012., Strategi Optimasi Wisata Massal di Kawasan Konservasi Taman Wisata Alam Grojogan SEWU. Jurnal Ilmu Lingkungan, Vol 10 (2): 100-110. http://ejournal.undip.ac.id/index.php/ilmulingkungan

(Gambar 1b). Kemudian disusul aspek ekologi dan ekonomi. Tingkat inkonsistensi 0,01 yang berarti lebih kecil dari 0,1 (batas maksimum) sehingga hasil analisis dapat diterima.

Secara umum, hasil analisis keseluruhan terhadap pilihan alternatif strategi menurut aspek ekonomi, aspek sosial dan aspek ekologi adalah sebagaimana Gambar 1c. Berdasarkan hasil analisis tersebut, maka terdapat tiga prioritas dalam strategi optimasi daya dukung wisata alam yaitu:

1. Peningkatan kapasitas ekonomi kreatif masyarakat lokal dengan nilai bobot $(0,254)$.

2. Penguatan stabilitas lereng dan perlindungan tanah, nilai bobot 0,228.

3. Menaikkan harga karcis masuk TWA, nilai bobot 0,134 .

Prioritas pertama adalah peningkatan kapasitas masyarakat dalam menghasilkan produk/jasa wisata yang kreatif dan inovatif akan meningkatkan nilai jual, menambah daya saing dan akan memberi kesan unik bagi wisatawan. Melimpahnya wisatawan bukan lagi menjadi tujuan bagi ekonomi lokal untuk memperbesar peluang terjadinya transaksi, namun mutu dan keunikan produk/jasa wisata-lah yang akan menjadi ikon pariwisata. Di sisi lain, dari segi ekologis, penguatan stabilitas lereng dan perlindungan tanah menjadi pilihan kedua. Sedangkan menaikkan harga karcis masuk TWA yang akan diharapkan mampu memperkecil jumlah wisatawan menjadi pilihan ketiga.

Pilihan ketiga merupakan hal yang menarik. BKSDA Jawa Tengah menginginkan untuk menaikkan harga karcis masuk untuk meningkatkan nilai perlindungan kawasan konservasi. Di sisi lain, pihak perusahaan menganggapnya belum perlu dinaikkan. Menurut Farrell dan Marion (2002), membatasi kunjungan dapat pula berarti melarang secara tidak perlu kebebasan pengunjung dan dapat menjadi sulit dan mahal untuk diterapkan. Melakukan pengurangan dan langkah tegas lain dalam melarang pengunjung juga akan dianggap sebagai ancaman potensial kepada pendapatan sektor pariwisata. Bagi negara berkembang, pendapatan ini merupakan pendapatan prioritas. Dan di bebarapa kasus, pembatasan ini gagal diterapkan dan tidak mendapat dukungan dari pengusaha atau masyarakat lokal.

Secara keseluruhan, nilai inkonsistensi adalah sebesar 0,06 sehingga hasil analisis dapat diterima. Selanjutnya hasil AHP ini dapat digunakan sebagai salah satu pertimbangan dalam penyusunan strategi optimasi daya dukung wisata alam TWA Grojogan Sewu.

Bagi pemerintah, PNBP telah menjadi indikator keberhasilan pengembangan pemanfaatan jasa lingkungan dan wisata alam. Namun visi menyejahterakan masyarakat juga menjadi indikator keberhasilan. Dua indikator keberhasilannya adalah (1) peningkatan pemberdayaan masyarakat dan wisata alam di sekitar kawasan konservasi dan (2) peningkatan pendapatan masyarakat di sekitar kawasan konservasi tertentu meningkat menjadi minimal Rp.800.000,- per bulan per kepala keluarga (atau sebesar 30\%) melalui upaya-upaya pemberdayaan masyarakat. Hal ini adalah sebagaimana dinyatakan dalam Rencana Strategis (Renstra) Kementerian Kehutanan Tahun 2010-2014.

Pungutan Pendapatan Negara Bukan Pajak (PNPB) terutama melalui karcis masuk, masih menjadi indikator utama setiap tahun terhadap keberhasilan pengusahaan pariwisata alam di Indonesia. Data Statistik Direktorat Pemanfaatan Jasa Lingkungan Kawasan Konservasi dan Hutan Lindung Dirjen PHKA Kementerian Tahun 2010 melaporkan bahwa pada tahun 2008, PNBP dari wisatawan dalam negeri di Taman Nasional dan Taman Wisata Alam adalah sebesar Rp. 7.866.720.000,sedangkan PNBP dari wisatawan luar negeri adalah sebesar Rp. 2.398.140.000,-. Total penerimaan PNBP dari sektor pariwisata alam adalah Rp. 10.264.860.000,-Dengan menggunakan indikator kinerja utama sebagaimana tersebut di atas, maka target penerimaan PNBP pada tahun 2014 harus meningkat 100\% atau menjadi sebesar lebih dari 20 milyar rupiah.

Hal yang sama juga dialami TWA Grojogan Sewu sebagaimana pada Gambar 3. Bila target izin baru pengusahaan wisata alam tidak tercapai, maka target penerimaan PNBP pada tahun 2014 akan ditopang dari para pemegang izin lama. Hal ini dapat berarti bahwa target penerimaan PNBP pada tahun 2014 di TWA Grojogan Sewu akan menjadi sebesar 100\% dari PNBP tahun 2008 yaitu akan menjadi sebesar 1,18 milyar rupiah. Dengan demikian, maka daya dukung wisata alam TWA Grojogan Sewu dipastikan akan telah melebihi 1.002 orang per hari.

Menurut Buckley (2010), di negara-negera berkembang, pariwisata komersial membentuk proporsi kecil kunjungan rekreasi ke kawasan konservasi dan tur operator skala kecil mengelola secara luas kepada pengunjung independen. Namun tekanan ke areal wisata dengan jumlah pengunjung yang semakin besar akan mempersulit kehendak politik untuk konservasi.

Keberdayaan masyarakat lokal dalam aktivitas pariwisata alam memegang peranan untuk mengoptimalkan pendapatan. Kemampuan untuk mengolah produk maupun jasa wisata secara kreatif akan mengubah paradigma semakin banyak pengunjung semakin besar peluang terjualnya produk atau jasa wisata. Perilaku para pedagang juga akan memberikan pengaruh pada pengembangan kewirausahaannya (Sapar, 2006). Masyarakat lokal khususnya Perdabita diharapkan lebih menitikberatkan kepada kualitas produk atau jasa dengan harga bersaing. Melalui ekonomi kreatif, diharapkan nilai keistimewaan produk atau jasa akan menjadi acuan jangka panjang. Kondisi yang dianggap lebih baik daripada berharap jangka pendek pada peluang terjualnya produk atau jasa dengan volume tinggi berkualitas rendah. Kualitas yang 
semakin baik akan semakin disukai wisatawan. Indikator peningkatan pendapatan masyarakat sekitar lokasi wisata sebesar $30 \%$ memungkinkan untuk dicapai.

Pengembangan produk dan jasa kreatif pariwisata menjadi momentum awal dalam menyambut progam pemerintah Jawa Tengah yaitu Program Visit Jawa Tengah 2013. Menurut Sekretariat Kabinet Republik Indonesia (2012), program ini ditujukan sebagai gerakan bersama pemerintah daerah dan masyarakat, dan dunia usaha melalui joint promotion, mempromosikan Jawa Tengah sebagai wilayah yang ideal untuk MICE (Meetings, Incentives, Conferences, and Exhibitions). Pencanangan Visit Jawa Tengah 2013 ini sangat didukung dengan keterhubungan transportasi udara di dua gerbang utama Jawa Tengah, yaitu Semarang dan Solo yang melayani rute langsung dari Malaysia dan Singapura. Visit Jawa Tengah 2013 akan menjadi bukti gerakan pemasaran pariwisata secara nasional yang semakin diikuti dengan kematangan berencana di daerahdaerah. Hal ini bisa dijadikan momentum untuk mempercepat pengembangan potensi pariwisata agar efektif menjadi kegiatan ekonomi, sekaligus kegiatan sosial dan seni budaya yang produktif. Dengan demikian daerah destinasi wisata juga harus mempercepat langkah melalui sektor pariwisata yang akan menggerakkan pertanian, membuka akses lapangan pekerjaan mengurangi kemiskinan dan menggalakkan kesenian dan budaya.

Diperlukan kerja sama pemerintah dan masyarakat penyedia sarana dan jasa wisata dalam hal ini termasuk Perdabita. Pemerintah dalam hal ini BKSDA Jawa Tengah dapat menginisiasi melalui kegiatan pemberdayaan masyarakat. Kerja sama dapat dilakukan antara BKSDA Jawa Tengah, PT Duta Indonesia Djaya, Dinas Pariwisata Kabupaten Karanganyar dan Perdabita. Selanjutnya perlu dilakukan kesepakatankesepakatan legal formal untuk memperjelas hak dan kewajiban para pihak dalam aktivitas pariwisata yang diparalelkan dengan ekonomi kreatif masyarakat lokal. Seperti halnya izin pengusahaan pariwisata alam, aktivitas Perdabita perlu dipertegas bentuk-bentuk kerja samanya dengan PT Duta Indonesia Jaya. Hal agar ketika ekonomi kreatif telah diimplementasikan dan tumbuh berkembang, maka tidak memunculkan konflik kepentingan berlabel pemberdayaan masyarakat. Diperlukan keterpaduan antara aspek ekonomi, aspek sosial dan aspek ekologi untuk mewujudkan pembangunan berkelanjutan Asdak (2012) yang hal ini dapat diawali dengan perencanaan ini secara sinergis.

Menurut Steck (1999), ketika dilakukan kerja sama pengelolaan dengan pengusaha swasta, maka harus diperjelas dalam wilayah apa sasaran pembangunan pariwisata berkelanjutan selaras dengan kepentingan ekonomi perusahaan dan di mana kecenderungan munculnya konflik. Hal ini berkaitan dengan pencegahan kerusakan sumber daya obyek wisata misalnya kerusakan landskap, polusi air, menganggu hidupan liar. Kesiapan fundamental untuk kerja sama operasional dengan komunitas lokal memang memiliki permasalahan. Bagi perusahaan, hal ini akan meningkatkan kompleksitas proses pengelolaan. Namun hal ini akan menguntungkan ketika kerja sama ini memberikan peluang untuk terciptanya produk dan jasa wisata yang menarik.

\section{Kesimpulan}

Berdasarkan uraian di atas dapat disimpulkan bahwa (1) Daya dukung efektif wisata alam TWA Grojogan Sewu adalah sebesar 1.002 orang per hari. Sedangkan kondisi riil berdasarkan rata-rata jumlah kunjungan wisatawan per hari adalah 926. Hal ini berarti daya dukung wisata alam belum terlampaui; (2) Persepsi para responden secara umum menunjukkan persepsi yang baik terhadap pengelolaan TWA. Khusus untuk wisatawan menyatakan kepuasan ketika berwisata (95\%) dan ingin kembali berkunjung (92\%); (3) Guna pengembangan pariwisata massal yang berkelanjutan, maka strategi yang dipilih adalah peningkatan kapasitas ekonomi kreatif masyarakat lokal.

\section{Ucapan Terimakasih}

Penulis juga menyampaikan terima kasih yang setinggitingginya kepada Prof. Dr. Ir. Purwanto, DEA selaku Ketua Program Studi Ilmu Lingkungan Universitas Diponegoro Semarang, Prof. Dr. dr. Anies, M.Kes,PKK selaku Direktur Program Pasca Sarjana Universitas Diponegoro Semarang, dan kepada Prof. Dr. Sudarto P. Hadi, MES selaku Rektor Universitas Diponegoro Semarang, yang telah memberikan kesempatan kepada penulis untuk mengikuti program pasca sarjana di Universitas Diponogoro Semarang. Juga kepada Kepala Pusat Pembinaan Pendidikan dan Pelatihan PerencanaBadan Perencanaan Pembangunan Nasional (Pusbindiklatren-Bappenas) dan Sekretaris Jenderal Kementerian Kehutanan beserta jajarannya atas beasiswa dan kesempatan belajar yang diberikan. Terima kasih juga penulis sampaikan kepada Kepala Balai Konservasi Sumber Daya Alam Jawa Tengah Direktora Jenderal PHKA Kementerian Kehutanan, Kepala Seksi Konservasi SDA Wilayah I Surakarta, Kepala Resor TWA Grojogan Dinas Pariwisata Kabupaten Karanganyar, Badan Lingkungan Hidup Kabupaten Karanganyar, Direktur PT Duta Indonesia Djaya Karanganyar, Persatuan Pedagang Bina Wisata TWA Grojogan Sewu atas kesediaannya menjadi objek dan kajian penelitian. 
Hariadi Siswantoro, Sutrisno Anggoro, Dwi P. Sasongko. 2012., Strategi Optimasi Wisata Massal di Kawasan Konservasi Taman Wisata Alam Grojogan SEWU. Jurnal Ilmu Lingkungan, Vol 10 (2): 100-110. http://ejournal.undip.ac.id/index.php/ilmulingkungan

\section{Daftar Pustaka}

Asdak, Chay. 2012. Kajian Lingkungan Hidup Strategis: Jalan Menuju Pembangunan Berkelanjutan. Gadjah Mada University Press. Yogyakarta.

BKSDA Jawa Tengah Dirjen PHKA Kementerian Kehutanan. 2009. Laporan Rencana Pengelolaan Jangka Panjang Taman Wisata Alam Grojogan Sewu Kabupaten Karanganyar Provinsi Jawa Tengah Periode 2009-2029. Semarang.

Buckley, Ralf. 2010. Conservation Tourism. CABI. Oxfordshire. United Kindom.

Cerina, Fabio; Markandya, Anil and McAleer, Michael (Editors). 2011. Economics of Sustainable Tourism. Routledge, New York, USA.

Cifuentes, Miquel. 1992. Determinacion de Capacidad de Carga Truistica en Areas Protegidas. Publicacion Patrocinada Por el Fondo Mundial para la Naturaleza-WWF. Serie Tecnica Informe Tecnico No. 194. Centro Agronomico Tropical de Investigacion Y Ensenanza CATIE, Programa de Manejo Integrado de Recursos Naturales. Turrialba, Costa Rica.

Djuwantoko; Utami, Retno Nur; Wiyono. 2008. Perilaku Agresif Monyet (Macaca fascicularis Rafles) terhadap Wisatawan di Hutan Wisata Alam Kaliurang, Yogyakarta. Biodiversitas 9 (4): 301305.

Duta Indonesia Djaya, Persero. 2009. Rencana Karya Pengusahaan Pariwisata Alam Tahun 2009-2029 di Zona/Blok Pemanfaatan Taman Wisata Alam Grojogan Sewu Tawangmangu Kabupaten Karanganyar Provinsi Jawa Tengah. PT Duta Indonesia Djaya. Karanganyar.

Fandeli, Chafid. 2000. Perencanaan Kepariwisataan Alam. Kursus Pengusahaan Ekowisata. Fakultas Kehutanan Universitas Gadjah Mada. Yogyakarta.

Fandeli, Chafid dan Muhammad. 2009. Prinsip-prinsip Dasar Mengkonservasi Lanskap. Gadjah Mada University Press. Yogyakarta.

Fandeli, Chafid dan Nurdin, Muhammad. 2005. Pengembangan Ekowisata Berbasis Konservasi di Taman Nasional. Fakultas Kehutanan Universitas Gadjah Mada, Pusat Studi Pariwisata Universitas Gadjah Mada dan Kantor Kementerian Lingkungan Hidup. Yogyakarta.

Fandeli, Chafid dan Suyanto, Agus. 1999. Kajian Daya Dukung Lingkungan Obyek dan Daya Tarik Wisata Taman Wisata Grojogan Sewu Tawangmangu. Manusia dan Lingkungan (19)/VII: 32-47.

Farrell, Tracy A; Marion, Jeffrey L. 2002. The Protected Area Visitor Impact Management (PAVIM) Framework: A Simplified Process for Making Management Decisions. Journal of Sustainable Tourism 10 (1): 31-51.

Gurung, Hum Bahadur. 2010. Trends in protected areas. CRC for Sustainable Tourism Pty Ltd. Gold Coast, Queensland, Australia.

Keraf, A.Sonny. 2010. Etika Lingkungan Hidup. Penerbit Buku Kompas. Jakarta
Khair, Uzunu. 2006. Kapasitas Daya Dukung Fisik Kawasan Ekowisata Di Taman Wisata Alam (TWA) Sibolangit Kabupaten Deli Serdang. Tesis. Sekolah Pasca Sarjana Universitas Sumatera Utara. Medan.

Lakitan, Benyamin. 1997. Dasar-dasar Klimatologi. Penerbit RajaGrafindo Persada. Jakarta.

Līvina, Agita (Ed). 2009. Sustainable Planning Instruments and Biodiversity Conservation. Vidzeme University of Applied Science, Latvia.

McCool, Stephen and Moisey, R. Neil (Ed). 2008. Tourism, recreation, and sustainability: linking culture and the environment 2nd edition. $\mathrm{CAB}$ International. Oxfordshire, United Kingdom.

Muta'ali, Lutfi. 2012. Daya Dukung Lingkungan untuk Perencanaan Pengembangan Wilayah. Badan Penerbit Fakultas Geografi Universitas Gadjah Mada. Yogyakarta.

Peraturan Menteri Kehutanan Nomor P.08/MenhutII/2010 Tentang Rencana Strategis (Renstra) Kementerian Kehutanan Tahun 2010-2014.

Pickering, Catherine Marina; Hill, Wendy. 2007. Impacts of recreation and tourism on plant biodiversity and vegetation in protected areas in Australia. Journal of Environmental Management 85: 791800 .

Rangkuti, Frederick. 1998. Analisa SWOT Teknik Membedah Kasus Bisnis. Gramedia Pustaka Utama. Jakarta.

Rosalino, Luis M and Grilo, Clara. 2011. What drives visitors to Protected Areas in Portugal: accessibilities, human pressure or natural resources? Journal of Tourism and Sustainability 1 (1): 3-11

Saaty, Thomas L. 1993. Pengambilan Keputusan Bagi Para Pemimpin: Proses Hirarki Analitik Untuk Pengambilan Keputusan dalam Situasi Yang Kompleks. Seri Managemen No. 134. PT. Pustaka Binaman Pressindo. Jakarta

Sayan, Mustafa Selcuk and Atik, Meryem. 2011. Recreation Carrying Capacity Estimates for Protected Areas: A Study of Termessos National Park (Turkey). Ekoloji 20 (78): 66-74.

Soemarwoto, Otto. 2004. Ekologi, Lingkungan Hidup dan Pembangunan Edisi ke-10. Penerbit Djambatan. Jakarta.

Steck, Birgit. 1999. Sustainable Tourism as a Development Option: Practical Guide for Local Planners, Developers and Decision Makers. Federal Ministry for Economic Co-operation and Development and Deutsche Gesellschaft für Technische Zusammenarbeit (GTZ) GmbH. Bonn, Jerman.

Subarsono, A.G. 2005. Analisis Kebijakan Publik. Pustaka Pelajar. Yogyakarta. 
Sustri. 2009. Daya Dukung Wisata Alam di Taman Nasional Kepulauan Togean Sulawesi Tengah. Tesis. Pasca Sarjana Ilmu Kehutanan Universitas Gadjah Mada. Yogyakarta. 